\title{
Prospects for Integrating Service Learning into Short-Term International Study
}

\author{
Donna M. Daly ${ }^{1}$, Suzanne Baker ${ }^{1} \&$ Stephen J. Williams ${ }^{1}$ \\ ${ }^{1}$ College of Health and Human Services Dean's Office, San Diego State University, San Diego, Ca., USA. \\ Correspondence: Donna M. Daly, College of Health and Human Services Dean's Office, San Diego State \\ University, San Diego, Ca., 92182-4124, USA. Tel: 1-619-594-6151. E-mail: ddaly@mail.sdsu.edu
}

Received: June 28, 2013

Accepted: November 6, $2013 \quad$ Online Published: February 12, 2014

doi:10.5539/jel.v3n1p16

URL: http://dx.doi.org/10.5539/jel.v3n1p16 "The best part of the trip was the community work...I would have liked to build more homes...lots of
meaningful things were exchanged between us and the community members."

Student Testimonials, La Gloria, Mexico (2009)

\begin{abstract}
In an era of significant social, political, and economic globalization, it is crucial for health and human services educators to adopt a more hands on international view vis-à-vis student education. This article presents information that will assist educators in extending domestic service learning concepts and activities into the undergraduate international study arena. The authors also introduce a research framework for further data collection and analysis. Finally, the article shares lessons learned and presents a continuum that features five milestones, institutional support, faculty buy-in, agency partnership, student engagement, and pre-post assessment that contribute to the successful incorporation of service learning activities.
\end{abstract}

Keywords: service learning, higher education internationalization, globalization of higher education

\section{Introduction}

We live in an era of social, political, and economic globalization which profoundly impacts domestic policies and international relationships. Technological advances enable innovative concepts and vast amounts of information to rapidly traverse the globe. This worldwide exchange provides opportunities to health and human services professionals for cross-fertilization of ideas, policies and practices, and for enhanced cultural awareness and sensitivity. Consequently, it is crucial for health and human services educators to adopt a more international view vis-à-vis student education. Although static exposure is beneficial, in international education this goal may be greatly enhanced using a more dynamic or interactive service learning approach. Service learning entails active student involvement in their exposure by being a participant rather than merely an observer; for example, by homebuilding with, rather than just watching, local people construct a home.

Study abroad components of educational programs are especially likely to benefit from service learning's effect of further integrating the impact of local experiences on student impressions and cultural exposures. To move from visiting and observation to direct involvement raises the bar on learning opportunities. This is especially valuable in client service and culturally dependent fields such as health care. However, meaningful service learning is an instructional challenge, especially in the context of short-term study abroad. Short-term experiences are critical in the health and human services fields owing to time and context limits in curriculum components relative to international education. For many students, only short-term programs are feasible.

The task of internationalizing health and human services education is especially challenging due to limited empirically-based models and research on developing successful international academic partnerships that fuse theory and practice. This article reviews prospects and shares lessons learned for integrating service learning into an undergraduate course featuring a short-term international study component. The context presented is generalizable to many other academic settings. Finally, research considerations and a framework for further data collection and analysis, recognizing the need to validate these concepts in an empirical context, are presented. 


\section{Service Learning}

The term "service learning," dating back to 1967 in earlier forms, denotes an experiential approach to education that is characterized by "reciprocal learning" (Sigmon, 1990). Although "service learning" has several definitions, it is critical to note that the concept involves more than just providing an important service to a community. Students must also derive an academic benefit, and the activity must contribute to civic participation and the pursuit of democratic citizenship in the sense of social responsibility (Howard, 2003).

\subsection{Benefits of Service Learning}

The benefits of service learning are well documented (Astin et al., 2000; Howard, 2003; Jacoby, 1996; Saltmarsh, 2005; Saltmarsh \& Zlotkowski, 2011). Astin et al. (2000) compared service learning with community service to identify the effects on student development in cognitive and affective areas. Quantitative and qualitative data were examined in a pre- and post- test design. Students engaged in domestic service learning showed positive effects in several key areas. Astin et al. (2000) presents an overview of the benefits of service learning and identifies the two most critical factors that are linked with a positive service learning experience - student interest in subject matter and instructor ability to facilitate discussions.

\section{Service Learning in Short-Term Study Abroad}

\subsection{International Service Learning}

A few researchers have examined the effects of participating in international service learning activities (Boyle et al., 1999; Bringle et al., 2011; Dyjack et al., 2001; Evanson \& Zust, 2004). Participants showed gains in the following areas: cultural awareness; understanding of social justice issues; motivation to pursue future service activities; and enhanced clarity vis-à-vis career path. All of the studies underscore the importance of student involvement in the process, flexible and involved faculty, and the use of curriculum that ties classroom learning to the field. These researchers also note that structured learning experiences, the identification of pre-departure research topics, and service learning goals, are enhanced by a deep reflection process during the field experience. Faculty-led discussions are also helpful tools for reinforcing learning and promoting critical thinking.

\subsection{Including Service Learning in Short-Term Study Abroad Programs}

There is a paucity of research that identifies the challenges and strategies associated with incorporating service learning into short-term study abroad. One study emphasizes the importance of facilitating a process for integrating conceptual and experiential learning via repeated faculty-led discussions (Smith-Pariola \& Goke-Pariola, 2006). It also underscores the importance of adequately preparing for service learning abroad by sharing history and culture, preparing counterparts abroad, providing a detailed explanation of service learning, and teaching basic research skills and research plan development. In essence, students are "deprogrammed" from traditional classroom roles and taught how to engage in non-traditional discussions when abroad (Smith-Pariola $\&$ Goke-Pariola, 2006).

\subsubsection{Benefits and Challenges in Integrating Service Learning and Study Abroad}

While there is limited literature specifically on undergraduate service learning in conjunction with study abroad, research documents the benefits and challenges of integrating service learning into short-term study abroad (Bringle et al., 2011; Brooking, 2010; Daly et al., 2013a; Evanson \& Zust, 2004; Lewis \& Niesenbaum, 2005; Smith-Pariola \& Goke-Pariola, 2006; Wessel, 2007). Some of the research describes student experiences and perceptions by conducting interviews and reviewing reflective journals (Brooking, 2010; Evanson \& Zust, 2004; Whitney \& Clayton, 2011). These researchers underscore the benefits of using "homestays" to enhance cultural learning and to increase student involvement. They also recommend integrating service activities throughout the program, encouraging leader-facilitated group reflection, and involving students directly in the preparation and planning of the service learning.

Like domestic service learning, international experience is a form of experiential education with increasing student participation. Bringle et al. (2011) have elevated the concept of international service learning in a book featuring a series of articles on design strategies that inform research on service learning in an international environment. The articles review both quantitative and qualitative approaches to gauging the effectiveness of international service learning (Eyler, 2011; Bringle et al., 2011; Kiely \& Hartman, 2011).

Evanson \& Zust (2004) examined international service learning among undergraduate nursing students. Students used journals, evening reflection, and faculty-led discussions to document learning. Students shared that service learning abroad clarified career path options, enhanced their understanding of globalization and social justice, motivated them to pursue service work, and facilitated a deeper understanding of reciprocal relationships and 
respect for the whole person. Lewis and Niesenbaum (2005) evaluated a short-term study abroad program that incorporated applied research and service learning and discovered that the experience motivated undergraduate students to alter their course of study, pursue subsequent travel abroad, seek interdisciplinary studies, and influenced their view of globalization. Students took a course where they were responsible for developing an interdisciplinary research project and a community service learning activity. Both of these studies reported that increased student involvement results in more meaningful personal and professional growth.

\subsubsection{Planning and Evaluation}

Carter et al. (2002) proposed five questions for planning service learning projects for college students regarding the weight assigned to project goals, mandatory versus voluntary participation, number of service learning sites, type of student participation (similar or different projects), and the level of interaction with clients and the community. Wessel (2004) added a sixth question regarding methods for evaluating student participation: international service learning includes the challenge of foreign language skills, an obstacle for some service learning placements.

There has been minimal research in the area of assessing international service learning outcomes. In a qualitative study funded by the Ford Foundation, Tonkin \& Quiroga (2004) found that service learning experience triggers students' growth and development in the following areas: cross-cultural communication, moral and ethical development, and critical thinking. They offer the following three suggestions: 1) increase the amount of communication, both pre-travel and post-travel, and maximize use of technology; 2) increase student involvement in the planning process; and 3) provide extensive pre-travel orientation and post-travel debriefing. They further note that evaluating international service learning is complex since long term transformations are not always immediately obvious. Short-term versus long-term outcomes is a key unknown at this time.

\section{Internationalizing Undergraduate Curriculum-"HHS 350"}

\subsection{The Setting}

The College of Health and Human Services (CHHS) at a large southwestern public university serves as the institutional focal point for "health sciences" education, featuring most of the applied fields related to health care and human services education, training, and research. These are the Schools of Social Work, Public Health, Nursing, Exercise and Nutritional Sciences, and Speech, Language, and Hearing Sciences. The college currently includes 4,111 undergraduate students and 965 graduate students. The college offers master's level programs in all five schools and a total of six doctoral programs in Exercise and Nutritional Sciences, Public Health, and Speech, Language, and Hearing Sciences.

The university has emphasized international education for some time and the current Strategic Plan has this as one of the top priorities. The CHHS has grappled with internationalizing the undergraduate curriculum of all units in the college while also seeking to offer an enhanced learning experience. Incorporating service learning components, primarily to offer more in-depth exposure and meaningful cultural experience, during short-term programs is a particularly notable challenge.

The CHHS implemented an international experience graduation requirement for all undergraduate students entering the college in Fall 2010 and thereafter, as previously described (Daly et al., 2013a; Daly et al., 2013b). Students are required to complete a minimum two-week, for-credit, international experience to meet the requirement. While studying abroad, students observe a number of different health and human service efforts and settings which might include, for example, community clinics, an orphanage, a migrant shelter, an HIV/AIDS clinic, and a children's hospital. They also have the opportunity to engage and interact with both local populations and health and human services providers in an international setting. Workplace diversity and globalization emphasize the importance of cultural awareness and competence. Additionally, the CHHS embraces studies that indicate that students who have participated in study abroad persist to graduation at higher rates and experience greater satisfaction with their education (Redden, 2010; Sutton \& Rubin, 2004).

\subsubsection{Undergraduate Course}

The CHHS designed and piloted an upper division undergraduate course, "Applied International Health and Human Services" (HHS 350), with a variety of travel locations to developed and developing countries including China, Costa Rica, India, Mexico, Switzerland, and Thailand. While HHS 350 is only one option that satisfies the college requirement, many students find it attractive given the focus on "health and human services" abroad.

The course was crafted to support and expand upon a university "Exploration of Human Experience" requirement. Explorations courses take the goals and skills of foundational courses to more advanced levels via 
greater interdisciplinary study and wider awareness of global concerns. Students electing to take HHS 350 also receive credit for completing a CSU Explorations course in the "cultural diversity" category.

HHS 350 explores worldwide economic, political, cultural, social, and health challenges, and provides students the opportunity to experience and witness these challenges first-hand in an international setting. The course is designed to offer a deeper understanding of the current global society in which we live and to inspire students to become active participants within this global sphere. Course topics covered include globalization, poverty and population, endemic diseases and epidemiological surveillance, international health care, global maternal and child health, international social services, cultural competence and sensitivity, and food security. The field portion of the course conducted in the international setting, complements and augments the extensive classroom content.

\subsubsection{Standards for Incorporating Service Learning}

The Council for the Advancement of Standards (CAS) in Higher Education sets standards and guidelines for college courses featuring service learning components. When crafting the HHS 350 curriculum, the college gave careful consideration to the following curriculum elements in Table 1.

Table 1. CAS standards and guidelines (2005)

- Service needs and nature of the work

- Desired service and learning outcomes

- Assignments that link service with academic process

- Opportunities for reflection

- Logistical issues (e.g., time, transportation, resources)

- Student roles and responsibilities

- Community member roles and responsibilities

- Risk management protocol

- Outcome evaluation process

\subsection{HHS 350: Learning Outcomes}

There is a natural partnership between the philosophy of service learning and the helping professions majors in the CHHS. The accreditation requirements for many of the college's majors, such as nursing, social work, and public health, include one or more undergraduate clinical or internship experience. Thus, students are accustomed to the value and importance of experiential learning as part of their undergraduate educational requirements.

HHS 350 was developed using an interdisciplinary approach. The course includes student learning outcomes that support knowledge, skills, and value acquisition as displayed in Table 2.

Table 2. HHS 350 learning outcomes

Knowledge

- Articulate an awareness of the interplay between social, cultural, economic, and political forces that shape health and human services worldwide and within the target region/country

- Explain the major issues and questions posed by the health and human services disciplinary approaches in the target region/country

- Acquire knowledge, appreciation, and acceptance of other cultures and traditions

- Critically and holistically examine potential causes of and solutions for current social issues and problems, e.g., migration, immigration, poverty, human rights, access to health care, and violence, from a global perspective and from the perspective of the inhabitants of the target community

- Identify existing services, and the merits and challenges of services and new programs needed to fill gaps in services 


\section{Skills}

- Think critically about the knowledge and skills learned in the context of another country/culture

- Apply the concepts and principles of health and human services disciplines in the analysis of the target region/country issues

- Understand and demonstrate culturally sensitive responses appropriate for HHS disciplines

- Identify with people and communities in need of services

Values

- Achieve the ethical conviction that enables constructive action for an international/global society

- Describe HHS values and how they relate to and guide practice

- Describe how values were developed, and how they differ from and are similar to those in different locales

\subsubsection{Classroom}

The classroom portion of HHS 350 includes extensive in-class lectures and group activities. Topics include those mentioned previously plus demographic trends, water and air quality, social service needs, cultural competence principles, and many other issues of global health and human services. Classroom instruction provides a context for the applied travel portion of the course but is, of necessity, not highly specific to each field location. Separately, and in smaller affiliated travel groups, students also review information about the country.

\subsubsection{Field}

The field portion of HHS 350 is held over winter, spring, or summer breaks. Students participate in service learning activities where feasible based on local conditions and arrangements while abroad to experience the profound effects of global community service. Examples of field work include home building, park clean up, and participation in socialization activities in schools and health services venues. In addition, students observe and interact with local health and human service players in a developing country. Each student draws from what they learn in the classroom to inform each experience in the field and witness international health and human services in action. Students come away from the field experience with authentic insight into a different culture and the diverse issues people in foreign countries face every day. Students participate in group discussions and individual reflection in such a manner as to integrate their service learning experience with other educational components, and in reflection of other participant's perceptions and insights.

HHS 350 currently features partial "service learning" components in the Mexico and Costa Rica travel locations, and homestays in Costa Rica. The bulk of course activities in other travel sites consist of volunteer work and shadowing health and human services professionals. Additional service learning components will be introduced into future delivery of the course. In this context, the intent is to increasingly transition from observation to service learning where practical. In some settings and functions, such as clinical care in a hospital, liability concerns limit student participation in some interactive activities.

\section{Research Framework}

\subsection{Background}

The CHHS international requirement was initially imposed in the Fall semester of 2010, and subsequently added for a large contingent of additional students in Fall semester of 2012. Only recent graduating students have had this obligation. As a result, only now are longer-term prospective evaluation data beginning to accumulate to allow for a more active analysis of the implications of the requirement and of the service learning component.

A dependable body of research exists regarding the impact of domestic service learning on student outcomes, indicating a moderate relationship between service learning and student development. Research regarding the impact of service learning on international study is a promising work in progress (Eyler, 2011; Bringle et al., 2011; Kiely \& Hartman, 2011).

\subsection{Proposed Framework}

Given the scant body of research measuring the value of international service learning, there is a need for data collection and analysis frameworks. Some insight may be obtained by reviewing the general body of domestic service learning literature. Collecting demographic information and surveying students with a Likert scale to 
gauge their attitudes regarding cultural sensitivity pre- and post- travel is a critical first step. The goal is to identify whether the addition of service learning changes student attitudes more than the experience of shadowing and visiting health and human services agencies alone.

Cultural competence and sensitivity are important skills for students and professionals in the health fields. Numerous theories have been proposed to explain the acquisition of cultural competence and sensitivity (Bennett, 1993; Hammer et al., 2003; Sinicrope et al., 2012). One well established quantitative approach for gauging intercultural competence was developed by Bennett (1993). It was further refined to include the measurement of intercultural sensitivity (Hammer et al., 2003).

\subsection{Proposed Tool and Analysis}

The Intercultural Development Inventory (IDI) is one approach with sound validity and reliability (Bennett, 1993). Table 3 provides sample items from this tool. The IDI, a 50 item Likert inventory, would be a practical tool to administer to large cohorts. It is proposed as a comprehensive instrument for collecting aggregate data along with relevant socio-demographic statistics. Multivariate analysis with the appropriate statistical techniques would then be used for assessing causal effect.

Table 3. Sample items from IDI

\begin{tabular}{lll}
\hline & Stage & Sample Item \\
\hline 1 & Denial & $\begin{array}{l}\text { I feel most comfortable living and working in a community where people look and act like } \\
\text { me }\end{array}$
\end{tabular}

2 Defense I believe that aid to developing countries should be targeted to those efforts that help these countries evolve towards they types of social, economic, and political systems that exist in the United States
3 Minimization I understand that difference exist [sic] but believe that we should focus on similarities. We are all human
4 Acceptance I believe that verbal and nonverbal behavior may vary across cultures and that all forms of such behavior are worthy of respect

5 Adaptation I have two or more cultural frames of reference and I feel positive about cultural differences

6 Integration I am able to analyze and evaluate situations from one or more chosen cultural perspectives

Source: Bennett (1993)

\subsection{Next Steps}

Domestic service learning research studies provide the foundation for international service learning research. A short-term international study experience, embedded within a college course, is an ideal laboratory for future data collection. The purpose here is to present a framework for further data collection and analysis. The next step is to validate these concepts in an empirical setting.

\section{Lessons Learned}

After each delivery of HHS 350, the course instructor administers an evaluation to gauge student perceptions, satisfaction, and achievement of learning outcomes. The instructor meets with the college's international coordinator and lead faculty to debrief and record "lessons learned." Table 4 summarizes the key lessons from these stakeholder meetings. These evaluations need to be extended to incorporate an assessment of any service learning components. 
Table 4. Enhancing service learning opportunities

\begin{tabular}{lll}
\hline Faculty & Partner Agencies & Students \\
\hline $\begin{array}{l}\text { Faculty support and buy-in are } \\
\text { critical }\end{array}$ & $\begin{array}{l}\text { Relationship development is a vital } \\
\text { part of the planning process }\end{array}$ & $\begin{array}{l}\text { Learning and living abroad is } \\
\text { enhanced by participation in social } \\
\text { and cultural events }\end{array}$ \\
\hline $\begin{array}{l}\text { Facilitation of evening discussions } \\
\text { tied to learning outcomes connects } \\
\text { theory to practice }\end{array}$ & $\begin{array}{l}\text { Sending a faculty member to do a } \\
\text { site visit prior to student travel is } \\
\text { essential }\end{array}$ & $\begin{array}{l}\text { "Value-added" activities include } \\
\text { home building, park clean up, and } \\
\text { activities in schools }\end{array}$ \\
\hline $\begin{array}{l}\text { Faculty benefit from training in risk } \\
\text { management }\end{array}$ & $\begin{array}{l}\text { Instructors accompany students } \\
\text { during travel to reinforce learning }\end{array}$ & $\begin{array}{l}\text { A reflection process and journal } \\
\text { writing with the use of "prompts" } \\
\text { are meaningful }\end{array}$ \\
\hline
\end{tabular}

To supplement these evaluations, researchers suggest the following additions when combining service learning with study abroad community service (Boyle et al., 1999; Smith-Pariola \& Goke-Pariola, 2006; Tonkin \& Quiroga, 2004; Wessel, 2007):

- teaching students about the difference between service learning and community service;

- adding student group work and reflections prior to travel to help prepare students and promote bonding;

- incorporating opportunities that "build service into learning and learning into service" such as home building, park clean up, and activities in schools and senior homes;

- identifying the research projects before travel and involving students in the "health and human services aspect of the research; and

- creating a linkage with an agency or university in the country to help identify service learning opportunities.

\section{Further Needs}

The benefits of integrating service learning into a study abroad experience are numerous based on the literature reviewed here and preliminary experience with CHHS students, despite challenges such as planning and coordination issues, logistical concerns, and limited resources. But, clearly, additional empirical justification is warranted given the time and logistics costs involved. The focus of this article has been to review prospects for integrating service learning specifically within an undergraduate study abroad requirement. An additional purpose was to survey the literature on service learning and study abroad, and to identify areas and potential methods for future research.

Brooking (2010) conducted qualitative research on short- term international service learning. Given that there is a dearth of literature in this area, there is a need for more research on benefits and outcomes since short-term programs are beginning to outnumber long-term programs. Other recommendations for future study include the following: 1) effect of international service learning on student global mindedness as measured by student actions, attitudes and beliefs; 2) effects of short-term versus long-term study abroad; 3) research on the role of international community partners vis-à-vis planning; and, 4) longitudinal studies documenting the long-term effects of short-term study abroad (Brooking, 2010).

Giles \& Eyler (1994) present several areas for service learning theory development and testing. These include the exploration of a developmental continuum for service learning, identifying the more salient characteristics of "interaction" during service learning, and studying how service learning might stimulate research inquiry. Other areas of interest include the impact of deep reflection during service learning and the contribution of service learning to improved citizenship.

Given the increase in study abroad, there is also a need for additional research on student learning outcomes. The 2004 Georgia Learning Outcomes of Students Studying Abroad Research Initiative study utilized a longitudinal comprehensive approach to examine study abroad learning outcomes (Sutton \& Rubin, 2004). The final report was delivered at a National Association of Foreign Student Advisers conference in June, 2010 (Sutton \& Rubin, 2010). This quantitative study recruited participants from the extensive University System of Georgia to review outcomes in the following content areas: knowledge of techniques for functioning in other cultures including intercultural interaction skills; understanding of global interdependence and comparative civics; and an awareness of world geography. Findings indicate that students with study abroad experience have improved 
academic performance, enhanced cross-cultural knowledge, and higher graduation rates than the control group. While the differences due to study abroad were true differences rather than effects of pre-existing group inequities, the researchers note that the findings are not axiomatic (Sutton \& Rubin, 2010).

Evanson \& Zust (2004) recommend further research to understand the effect of meaningful international service learning on subsequent personal and professional life endeavors. Wessel (2007) notes the important issue of "culture shock" abroad, a significant part of the learning process abroad. Finally, Tonkin \& Quiroga (2004) suggest that the evaluation process for international service learning is challenging as it is difficult to measure the effects of a transformative experience as well as the long lasting changes.

Kahn (2011) advocates for addressing the hidden networks at play including cultural systems and ideologies. A "visual approach" with methodological and theoretical roots is a critical planning tool. Visual methods for objectifying student knowledge and experiential learning include capturing photos and video clips.

\subsection{Conclusions}

There are a number of conclusions based on this literature review and the anecdotal experience gleaned from HHS 350. While the benefits of integrating service learning into study abroad likely outweigh the logistical and time allocation concerns, adding service learning into a short-term study abroad experience is further challenged by the limited time abroad. As noted, there is a need for additional quantitative and qualitative research that documents benefits and student learning outcomes. Longitudinal studies are needed to support effects over time. Course evaluations that do more than gauge student satisfaction will help reveal the effect of service learning abroad on the transfer of learning and the impact on future practice in the health and human services arena.

\section{Service Learning Integration Continuum}

Daly, et al. (2013) identified a synergy between three milestones, academic agenda, student personal goals, and an institutional goal of globalization, that contribute to the successful execution of a college-wide international mandate. Extending this formula, additional indicators that facilitate the successful integration of service learning into an undergraduate international experience are summarized in Figure 1. Inadequacies in the areas noted are likely to contribute to partial integration or a strictly "community service experience." Each of these five milestones (i.e., institutional support, faculty buy-in, agency partnership, student engagement, and pre-post assessment) is a necessity for successful integration.

\subsection{Integration Milestones}

Institutional support is the catalyst for ensuring faculty buy-in. Following the support and proper training of faculty, the development of an agency partnership abroad is critical. Student engagement is facilitated by incorporating "value-added" active participant activities such as home-building and by including social and cultural events. Students are further engaged via reflective activities such as journal writing and facilitated group discussions that link the positive effects of service learning to academic performance, values, leadership, and future career decisions. Finally, pre- and post-assessment activities enable educators to gauge learning outcomes and improve the curriculum and field work aspects of the course. The five milestones depicted in Figure 1 contribute to the successful incorporation of service learning activities into short-term study abroad. 


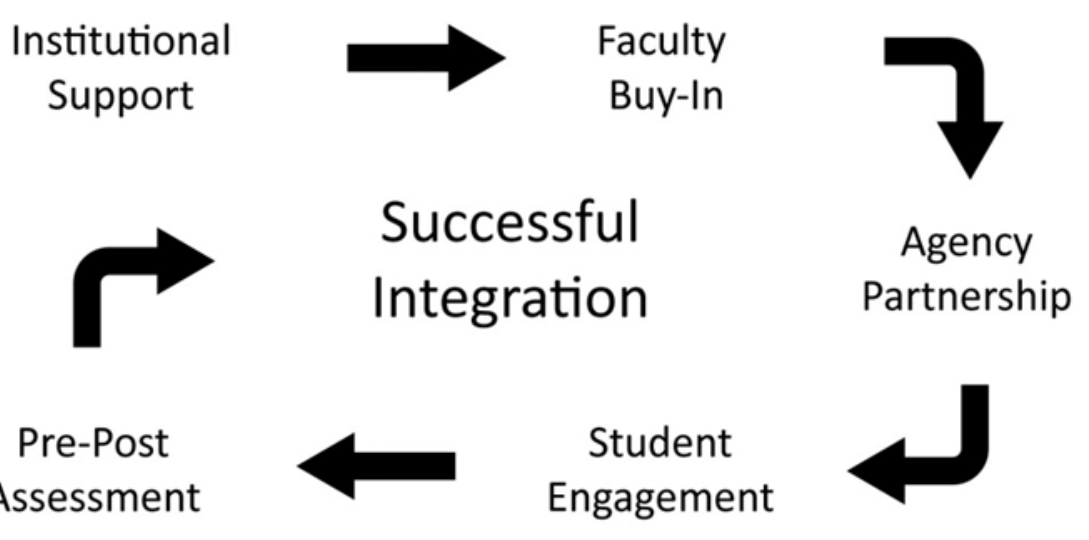

Figure 1. From international experience to international service learning: A Continuum

Short-term study aboard has been demonstrated to have value and be an effective approach to global experiences. But based on the literature and the preliminary experience, the benefit is clearly enhanced through the integration of service learning opportunities. The practical limits of the location, time frame, teaching moments, and other factors may present challenges, but do not exclude the integration of appropriate levels of service learning as a component of the larger experience.

The conceptual underpinnings of adding service learning to student international experiences outlined here are drawn from a limited but consistent literature supportive of the educational principles upon which service learning is based. Further empirical evidence, following the direction provided here, to confirm these expectations will solidify the fundamental concepts of education proposed here and supported by the preliminary information presented.

\subsubsection{Final Note}

Despite some challenges, the prospects for integrating service learning into short-term undergraduate study abroad hold tremendous promise for student transformation. It is essential for educators in the health and human services realm to adopt a more international view vis-à-vis student education to keep pace with the current era of social, political, and economic globalization. With demands for increased accountability in higher education, this is an area that holds prospects for demonstrable value added from a degree program. A more global-minded stance, along with the milestones presented in the aforementioned continuum, will provide more insightful opportunities for health and human services professionals in the future.

\section{References}

Astin, A., Vogelgesang, L., Ikeda, E., \& Lee, J. (2000). How service learning affects students (Executive Summary). Retrieved June 15, 2011, from http://74.125.155.132/scholar?q=cache:asOCTBQDPL0J:scholar.google.com/+How+service+learning+affe cts+students, + Astin, + et.+al., $+2000 \&$ hl $=$ en\&as_sdt $=0,5$

Bennett, J. M. (1993). Toward ethnorelativism: A developmental model of intercultural sensitivity. In R. M. Paige (Ed.), Education for the intercultural experience (pp. 21-71). Yarmouth, ME: Intercultural.

Boyle, D., Nackerud, L., \& Kilpatrick, A. (1999). The road less traveled: Cross-cultural, international experiential learning. International Social Work, 42(2), 201-214. http://dx.doi.org/10.1177/002087289904200208

Bringle, R. G., Hatcher, J. A., \& Williams, M. J. (2011). Quantitative approaches to research on international service learning. In R. G. Bringle, J. A. Hatcher, \& S. G. Jones (Eds.), International Service Learning (pp. 275-290). Sterling, VA: Stylus.

Brooking, D. (2010). Experiential learning in an international context: College student experiences in short term international service learning programs (Doctoral dissertation). Retrieved from ProQuest Dissertations and Theses databases. (AAT No. 3439802). 
Carter, M., Rivero, E., Cadge, W., \& Curran, S. (2002). Designing your community learning project: Five questions to ask about your pedagogical and participatory goals. Teaching Sociology, 30, 158-173. http://dx.doi.org/10.2307/3211380

Daly, D. M., Baker, S., \& Williams, S. J. (2013a, Spring). An international experience mandate for undergraduates in a college of health and human services: Initial assessment. Journal of Education and Learning, 2(1), 44-54. http://dx.doi.org/10.5539/jel.v2n1p44

Daly, D. M., Baker, S., \& Williams, S. J. (2013b, Summer). A prescription for global education in health and human services. About Campus, 18(3), 19-24. http://dx.doi.org/10.1002/abc.21120

Dewey, J. (1916). Democracy and Education. New York, NY: The Macmillan Company.

Dyjack, D., Anderson, B., \& Madrid, A. (2001). Experiential public health study abroad education: Strategies for integrating theory and practice. Journal of Studies in International Education, 5, 244-254. http://dx.doi.org/10.1177/102831530153005

Evanson, T. A., \& Zust, B. L. (2004). The meaning of participation in an international service experience among baccalaureate nursing students. International Journal of Nursing Education Scholarship, 1(1), 1-14.

Eyler, J. (2011). What international service learning research can learn from research on service learning. In R. G. Bringle, J. A. Hatcher, \& S. G. Jones (Eds.), International Service Learning (pp. 225-241). Sterling, VA: Stylus.

Giles, D. E., \& Eyler, J. S. (1994). The impact of a college community service laboratory on students' personal, social, and cognitive outcomes. Journal of Adolescence, 17, 327-339. http://dx.doi.org/10.1006/jado.1994.1030

Hammer, M. R., Bennett, J. M., \& Wiseman, R. (2003). Measuring intercultural sensitivity: The intercultural development inventory. International Journal of Intercultural Relations. 27, 421-443. http://dx.doi.org/10.1016\%2FS0147-1767\%2803\%2900032-4

Howard, J. (2003). Service learning research: Foundational issues. In S. H. Billig, \& A. S. Waterman (Eds.), Studying service learning: Innovations in education research methodology (pp. 1-12). Mahwah, NJ: Lawrence Erlbaum Associates, Inc., Publishers.

Jacoby, B. (1996). Service learning in today's higher education. In B. A. Jacoby (Ed.), Service learning in higher education: Concepts and practices (pp. 3-25). San Francisco: Jossey-Bass, Inc., Publishers.

Kahn, H. E. (2011). Overcoming the challenges of international service learning: A visual approach to sharing authority, community development and global learning. In R. G. Bringle, J. A. Hatcher, \& S. G. Jones (Eds.), International service learning: Conceptual frameworks and research (pp. 113-124). Sterling, Virginia: Stylus.

Kiely, R., \& Hartman, E. (2011). Qualitative research methodology and international service learning: Concepts, characteristics, Methods, Approaches, and Best Practices. In R. G. Bringle, J. A. Hatcher, \& S. G. Jones (Eds.), International Service Learning (pp. 275-290). Sterling, VA: Stylus.

Lewis, T., \& Niesenbaum, R. (2005). Extending the stay: Using community-based research and service learning to enhance short-term study abroad. Journal of Studies in International Education, 9, 251-264. http://dx.doi.org/10.1177/1028315305277682

Redden, E. (2010). Academic outcomes of study abroad. Inside Higher Education. Retrieved from http://www.insidehighered.com/news

Saltmarsh, J. (2005). The civic promise of service learning. Liberal Education, 50-55.

Saltmarsh, J., \& Zolotski. (2011). Higher education and democracy: Essays on service-learning and civic engagement. Philadelphia, PA: Temple University Press.

Service-learning programs: CAS standards and guidelines. (2005). Council for the Advancement of Standards in Higher Education.

Sigmon, R. L. (1990). Service learning: Three principles. In J. C. Kendall, \& Associates (Eds.), Combining Service and Learning: A Resource Book for Community and Public Service (Vol. 1, pp. 37-56). Raleigh, North Carolina: National Society for Internships and Experiential Education. 
Sinicrope, C., Norris, J., \& Watanabe, Y. (2012). Understanding and assessing intercultural competence: A summary of theory, research, and practice. Unpublished manuscript. University of Hawaii at Manoa, Honolulu, Hawaii.

Smith-Pariola, J., \& Goke-Pariola, A. (2006). Expanding the parameters of service learning: A case study. Journal of Studies in International Education, 10, 71-86. http://dx.doi.org/10.1177/1028315305283307

Sutton, R. C., \& Rubin, D. L. (2010). Documenting the academic impact of study abroad: Final report of the GLOSSARI project. NAFSA Conference, June 4, 2010. Retrieved on September 15, 2011, from http://glossari.uga.edu/datasets/pdfs/FINAL.pdf

Sutton, R. C., \& Rubin, D. L. (2004). The GLOSSARI project: Initial findings from a System-Wide Research Initiative on Study Abroad Learning Outcomes. Frontiers: The Interdisciplinary Journal of International Education, 65-82.

Tonkin, H., \& Quiroga, D. (2004). A qualitative approach to the assessment of international service-learning. Frontiers: The interdisciplinary journal of study abroad, 10, 131-149.

Wessel, N. (2007) Integrating service learning into the study abroad program: U.S. sociology students in Mexico. Journal of Studies in International Education, 11, 73-89. http://dx.doi.org/10.1177/1028315305283306

Whitney, B. C., \& Clayton, P. H. (2011). Research on and through reflection in international service learning. In R. G. Bringle, J. A. Hatcher \& S. G. Jones (Eds.), International service learning: Conceptual frameworks and research (pp. 145-187). Sterling, Virginia: Stylus.

\section{Copyrights}

Copyright for this article is retained by the author(s), with first publication rights granted to the journal.

This is an open-access article distributed under the terms and conditions of the Creative Commons Attribution license (http://creativecommons.org/licenses/by/3.0/). 